\title{
Haemodynamic and metabolic effects in diabetic ketoacidosis in rats of treatment with sodium bicarbonate or a mixture of sodium bicarbonate and sodium carbonate
}

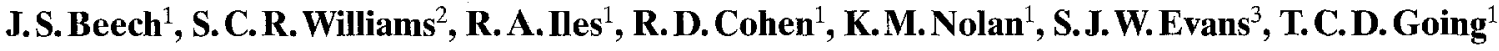 \\ ${ }^{1}$ Cellular Mechanisms Research Group, The London Hospital Medical College, London, UK \\ ${ }^{2}$ Magnetic Resonance Spectroscopy Unit, Queen Mary and Westfield College, University of London, London, UK \\ ${ }^{3}$ Department of Epidemiology and Medical Statistics, The London Hospital Medical College, London, UK
}

\begin{abstract}
Summary To examine factors determining the haemodynamic and metabolic responses to treatment of diabetic ketoacidosis with alkali, groups of anaesthetised and ventilated rats with either diabetic ketoacidosis (mean arterial $\mathrm{pH}$ 6.86-6.96, mean arterial blood pressure $63-67 \mathrm{~mm} \mathrm{Hg}$ ) or hypovolaemic shock due to blood withdrawal (mean $\mathrm{pH}_{\mathrm{a}} 7.25-7.27$, mean arterial blood pressure $36-41 \mathrm{~mm} \mathrm{Hg}$ ) were treated with sodium chloride ('saline'), sodium bicarbonate or 'Carbicarb' (equimolar bicarbonate plus carbonate). In the diabetic ketoacidosis series, treatment with either alkali resulted in deterioration of mean arterial blood pressure and substantial elevation of blood lactate, despite a significant rise in myocardial intracellular $\mathrm{pH}$ determined by ${ }^{31} \mathrm{P}$-magnetic resonance spectroscopy. These effects were accompanied by falling trends in the ratios of myocardial phosphocreatine and ATP to inorganic phosphate. Erythrocyte 2,3-bisphosphoglycerate was virtually absent in animals with diabetic ketoacidosis of this se-
\end{abstract}

verity and duration. In contrast, in shock due to blood withdrawal, infusion of saline or either alkali was accompanied by a transient elevation of mean arterial blood pressure and no significant change in the already elevated blood lactate; erythrocyte 2,3-bisphosphoglycerate was normal in these animals. The effect of alkalinization in rats with severe diabetic ketoacidosis was consistent with myocardial hypoxia, due to the combination of very low initial erythrocyte 2,3bisphosphoglycerate, alkali-exacerbated left shift of the haemoglobin-oxygen dissociation curve and artificial ventilation. No evidence was found for any beneficial effect of 'Carbicarb' in either series of animals; 'Carbicarb' and sodium bicarbonate could be deleterious in metabolic acidosis of more than short duration. [Diabetologia (1995) 38: 889-898]

Key words Diabetic ketoacidosis, lactic acidosis, hypovolaemic shock, bicarbonates, magnetic resonance spectroscopy, myocardium/metabolism.
Though therapy for clinical diabetic ketoacidosis (DKA) seldom includes alkalinization if the arterial $\mathrm{pH}$ exceeds 7.0, there is less consensus when the systemic acidosis is more severe $[1,2]$. The studies by

Received: 18 October 1994 and in revised form 23 January 1995

Corresponding author: Professor R. D. Cohen, Medical Unit, The Royal London Hospital, Whitechapel Road, London E1 1BB, UK

Abbreviations: DKA, Diabetic ketoacidosis; 2,3-BPG, 2,3-bisphosphoglycerate; $\mathrm{pH}_{\mathrm{a}}$, arterial $\mathrm{pH} ; \mathrm{pH}_{\mathrm{i}}$, intracellular $\mathrm{pH}$; $\mathrm{P}_{\mathrm{a}} \mathrm{CO}_{2}$, arterial $\mathrm{PCO}_{2} ; \mathrm{Pi}$, inorganic phosphate; $\mathrm{PCr}$, phosphocreatine; MRS, magnetic resonance spectroscopy; MABP, mean arterial blood pressure.
Arieff et al. $[3,4]$ have cast doubt on the value of sodium bicarbonate in the treatment of metabolic acidosis [5]. In both experimental phenformin-induced lactic acidosis and in lactic acidosis induced by the breathing of hypoxic gas mixtures, sodium bicarbonate treatment was disadvantageous compared with saline in respect of haemodynamics, blood lactate and hepatic intracellular $\mathrm{pH}$. Because some have argued [6-9] that the deleterious effect of sodium bicarbonate is due to its immediate effect in elevating arterial $\mathrm{PCO}_{2}\left(\mathrm{P}_{\mathrm{a}} \mathrm{CO}_{2}\right)$, with consequent intracellular acidification, therapies which avoid this effect have been developed. Of these, an equimolar mixture of sodium carbonate and sodium bicarbonate, devised by Filley and Kindig [6] and named 'Carbicarb' is 
the best known. Comparisons of the effects of saline, sodium bicarbonate and 'Carbicarb' have been made in several animal models [10-12]. However, few of these have attempted to emulate the severe acidosis, circulatory insufficiency and duration of acidosis which are common features of clinical DKA, in which decisions on alkalinizing therapy have currently to be made on an empirical basis. The purpose of the present studies was to identify some of the factors which could determine the response to sodium bicarbonate and to 'Carbicarb' in such circumstances.

There is evidence that the deleterious effects of acidosis on haemodynamics and aspects of metabolism are related to falls in intracellular $\mathrm{pH}\left(\mathrm{pH}_{\mathrm{i}}\right)$ in critical organs. Specifically, this appears to be the case for the negative inotropic effect of systemic acidosis $[13,14]$ and for the inhibition of hepatic gluconeogenesis from lactate $[15,16]$. It is therefore a testable hypothesis that therapies which correct intracellular acidosis are advantageous in haemodynamic and metabolic terms. It should be noted that, apparently uniquely in DKA, hepatic $\mathrm{pH}_{\mathrm{i}}$ does not fall appreciably, despite severe systemic acidosis [17]; there is no reason, however, to suppose that this protection extends to myocardial $\mathrm{pH}_{\mathrm{i}}$.

For this reason, in the present study we measured myocardial $\mathrm{pH}_{\mathrm{i}}$ and indices of energy metabolism, together with blood pressure and blood lactate before and after therapy in rats with severe diabetic ketoacidosis induced over $48 \mathrm{~h}$. For comparison with a much more acute acidosis, we also report observations using the same treatment regimens in rats with lactic acidosis due to hypovolaemia induced by withdrawal of blood.

\section{Materials and methods}

Diabetic ketoacidosis model. Male Wistar rats (weight approximately $400 \mathrm{~g}$ ) were rendered diabetic by a single intravenous injection of streptozotocin $(100 \mathrm{mg} / \mathrm{kg})$ and were then starved for $48 \mathrm{~h}$, by which time severe diabetic ketoacidosis (DKA) had developed. The rats were then anaesthetised with pentobarbitone $(60 \mathrm{mg} / \mathrm{kg})$ and a jugular vein and carotid artery cannulated, before preparation for magnetic resonance observations of cardiac intracellular $\mathrm{pH}\left(\mathrm{pH}_{\mathrm{i}}\right)$ and high energy phosphates. An arterial blood sample was then obtained and arterial blood $\mathrm{pH}\left(\mathrm{pH}_{\mathrm{a}}\right)$ and $\mathrm{P}_{\mathrm{a}} \mathrm{CO}_{2}$ determined. A tracheostomy was performed and artificial ventilation established, using a ventilation frequency of $58 / \mathrm{min}$ and a variable stroke volume. Through a mid-line sternotomy an 8-mm diameter surface coil was placed over and in contact with the left ventricle and the edges of the wound held slightly apart with a brass self-retaining retractor. Neuromuscular blockade was induced with pancuronium $(4 \mathrm{mg} / \mathrm{kg})$. The stroke volume of the ventilator was then adjusted to give the same $\mathrm{P}_{\mathrm{a}} \mathrm{CO}_{2}$ as had been observed before surgery. Three samples of arterial blood were taken over the next $15 \mathrm{~min}$ for measurement of $\mathrm{pH}_{\mathrm{a}}, \mathrm{P}_{\mathrm{a}} \mathrm{CO}_{2}$, bicarbonate $\left(\left[\mathrm{HCO}_{3}{ }^{-}\right]_{\mathrm{a}}\right)$, glucose, lactate and 3-hydroxybutyrate. Mean arterial blood pressure was recorded via the carotid cannula us- ing a Statham strain gauge. The animal was then positioned in a supine position in the bore of the magnetic resonance spectrometer (see below), and a baseline measurement of myocardial $\mathrm{pH}_{\mathrm{i}}$ was obtained as described below.

The animals were then assigned to one of three treatment groups. Group 1 received an intravenous infusion $(3-6 \mathrm{mmol} /$ $\mathrm{kg}$ ) of $1 \mathrm{~mol} / \mathrm{l}$ sodium chloride ('saline') over $3 \mathrm{~min}$. Group 2 received sodium bicarbonate, $1 \mathrm{~mol} / \mathrm{l}$, and Group 3 'Carbicarb' (solution containing $0.33 \mathrm{~mol} / \mathrm{l}$ sodium bicarbonate and $0.33 \mathrm{~mol} / \mathrm{l}$ sodium carbonate - i. e. equivalent in base per litre to $1 \mathrm{~mol} / 1$ sodium bicarbonate) in volumes over $3 \mathrm{~min}$ calculated to correct the plasma bicarbonate to $25 \mathrm{mmol} / 1$, using the following formula:

$$
\text { Alkali }(\mathrm{ml})=\text { weight }(\mathrm{kg}) \times 0.4 \times\left[25-\left[\mathrm{HCO}_{3}{ }^{-}\right]_{\mathrm{a}}\right\}
$$

Typically, the amount of alkali infused was $3-6 \mathrm{mmol} / \mathrm{kg}$.

A further measurement of myocardial $\mathrm{pH}_{i}$ was made over the $18 \mathrm{~min}$ following the infusion.

${ }^{31}$ P-magnetic resonance spectrometry (MRS) studies. These were performed at $81 \mathrm{MHz}$ in a $4.7 \mathrm{~T} 30-\mathrm{cm}$ diameter horizontal bore superconducting magnet controlled by a SISCO 200 imaging spectrometer. The rat was positioned in the probe on a warm pad and the heart monitored by ECG throughout. Myocardial $\mathrm{pH}_{\mathrm{i}}$ was measured by determination of the $\mathrm{pH}$-dependent chemical shift of the phosphorus resonance of inorganic phosphate $(\mathrm{Pi})$ with respect to phosphocreatine. We used the technique described by Zahler et al. $[18,19]$ to abstract the signal due to myocardial $\mathrm{Pi}$ from the combined signal due to blood Pi and 2,3-bisphosphoglycerate and myocardial Pi. The principle is to apply a long selective radiofrequency pulse which saturates the signals from these three resonances of comparable chemical shift. If a delay of sufficient length is then incorporated before inserting another (non-selective) radiofrequency read-out pulse, the blood containing the previously saturated $\mathrm{Pi}$ and 2,3-bisphosphoglycerate (2,3-BPG) phosporus nuclei will have moved on from the region of interest; fresh blood entering the heart will be unsaturated and will therefore result in an observable resonance, whereas the Pi within the myocardium remains saturated, thus yielding a negligible signal contribution. If the frequency of the saturating pulse is then moved to a point in the spectrum remote from $\mathrm{Pi}$ and 2,3-bisphosphoglycerate (in practice to the position of the $\beta$-ATP signal, $22 \mathrm{ppm}$ upfield from $\mathrm{Pi}$ and 2,3-bisphosphoglycerate), and the protocol repeated, the spectrum recorded will contain the combined signal described above. Subtraction of the first spectrum from the second yields the myocardial Pi peak, from which the $\mathrm{pH}_{\mathrm{i}}$ can be obtained. The technique assumes that the signal contributed by $\mathrm{Pi}$ in the myocardial interstitial space and capillaries is small compared with that from within cardiac myocytes. In practice, the position of the saturating pulse was alternated every four scans. Since the heart rate is slowed in severely acidotic rats (mean 271 beats per $\mathrm{min}$ in three rats with arterial $\mathrm{pH} 6.69-6.88$, compared with $\approx 360$ beats per min in normal animals), the length of the delay after the saturation pulse required consideration. Measurement of left ventricular dimensions in diastole and systole in a cine-magnetic resonance image sequence of normal rat heart indicated an ejection fraction between 70 and $60 \%$ (Beech, unpublished observations). After two beats, therefore, residual saturation was well below $10 \%$. Together with the observation that the mean $\mathrm{Pi}$ signal from ventricular blood is relatively small compared with the total Pi signal (median $6 \%$, range $<4-34 \%$ pre-infusion, median $24.5 \%$, range $<4-49 \%$ post-infusion; $n=16$ ), this data suggested that a delay of $450 \mathrm{~ms}$, as employed by Zahler et al. [18] was adequate, and 
this would still be the case if the ejection fraction was as low as $40 \%$ in acidotic rats. A delay of $450 \mathrm{~ms}$ was therefore used in all the cardiac MRS studies. A pulse repetition time of $1.96 \mathrm{~s}$ was employed and an 18-min total acquisition time was needed to obtain adequate signal/noise ratio (256 repetitions). The duration of the non-selective pulse was $17 \mu \mathrm{s}$. Since the post-infusion period does not represent a steady state, the $\mathrm{pH}_{\mathrm{i}}$ measurement has to be regarded as a time average over that period. $\mathrm{pH}_{\mathrm{i}}$ was determined by a computer programme which automatically detects the peak value of the Pi resonance and compares the chemical shift with the computer-held titration curve of $P i$.

Estimates of myocardial phosphocreatine (PCr), ATP and Pi were made by measurement of peak areas in the spectra obtained before and after infusion. In the case of $P_{i}$, the subtraction spectrum was used. For PCr and ATP the spectrum obtained when the saturation pulse was in the $\mathrm{Pi} / 2,3$-bisphosphoglycerate position was employed. For technical reasons it is not possible to use the the subtraction spectrum for ATP, so the assumption was made, as did Zahler et al. [19] when interpreting the effects of treatment on myocardial ATP, that erythrocyte ATP changes are not different between the groups and are in any case small. The results are expressed as $\mathrm{PCr} / \mathrm{ATP}, \mathrm{PCr} / \mathrm{Pi}$ and ATP/Pi for this method.

At the end of the post-infusion period the animal was removed from the spectrometer and a further $1 \mathrm{ml}$ of arterial blood was obtained for repeat measurement of acid base variables, lactate and 3-hydroxybutyrate, and mean arterial blood pressure.

Since it was not practicable to make frequent observations whilst the animal was in the spectrometer, a further series of experiments was performed in which the procedures were identical in all respects, including the sternotomy and artificial ventilation, except for the taking of serial blood samples ( $200 \mu \mathrm{l}$, replaced by saline) and the animal not being placed in the spectrometer. These studies are referred to as 'bench' experiments.

Hypovolaemic shock model. Rats were anaesthetized, sternotomy performed and artificial ventilation instituted as for the DKA model. They were then rendered hypovolaemic by successive withdrawal of blood from the jugular vein over about $30 \mathrm{~min}$ in a manner previously described [20], until the mean arterial blood pressure, recorded with a Statham strain gauge reached $40 \mathrm{mmHg}$. A $60-120 \mathrm{~min}$ period was allowed to elapse until $\mathrm{pH}_{\mathrm{a}}$ was in the range 7.2-7.3. Groups of animals then received the same treatment regimens as for the diabetic ketoacidosis model. It did not prove possible to maintain the majority of these severely hypovolaemic animals in a stable condition in the spectrometer. However, we were able to make observations in 'bench' experiments as for the diabetic animals. The sternotomy and artificial ventilation were employed to permit comparison of the bench experiments in the DKA and hypovolaemic series.

Analytical methods. $\mathrm{pH}_{2}, \mathrm{P}_{\mathrm{a}} \mathrm{CO}_{2}$ and $\left[\mathrm{HCO}_{3}{ }^{-}\right]_{\mathrm{a}}$ were measured with an IL 1304 blood gas analyser. Lactate and 3-hydroxybutyrate were measured on perchloric acid extracts of whole blood by standard enzymatic methods [21, 22]. All reagents were of analytical grade. For measurements of erythrocyte 2,3-bisphosphoglycerate (2,3-BPG), approximately $5 \mathrm{ml}$ arterial blood was taken into preweighted tubes containing $10 \mathrm{ml}$ $0.6 \mathrm{~mol} / \mathrm{l}$ perchloric acid, which were then reweighed, and centrifuged. Neutralized perchlorate extract $(4 \mathrm{ml})$ was then placed in a Bruker AM250 high field magnetic resonance spectrometer and ${ }^{31} \mathrm{P}$ spectra accumulated at $100 \mathrm{MHz}$, using a simple pulse-acquire sequence. Phosphocreatine $(5 \mathrm{mmol} / \mathrm{l})$ was used both as an internal standard and a chemical shift reference. Comparison of peak areas of the signals from the 3-phosphate of 2,3-BPG and phosphocreatine was used to estimate 2,3-BPG concentration. Haemoglobin and packed cell volume were measured using a Coulter counter and 2,3-BPG expressed as $\mathrm{mmol} / \mathrm{l}$ blood or $\mathrm{mol} / \mathrm{mol}$ haemoglobin.

\section{Statistical analysis}

For comparing means within the same treatment group in the MRS studies before and after infusion, two-tailed paired $t$ test were used. Comparison of post-treatment means between groups was performed using analysis of covariance, adjusting for differences in pre-treatment values. Analysis of variance was used to compare treatment effects between treatment groups. For comparing the effects of different treatments in the bench experiments, the method of summary statistics with analysis of covariance was used [23,24]. The summary statistic employed was the mean of all the data for a given variable from 2 to $20 \mathrm{~min}$. The baseline value of the variable was used as a covariate.

\section{Results}

\section{Diabetic ketoacidosis}

MRS observations. Figure 1 shows the spectra obtained with and without suppression of the myocardial inorganic phosphate (Pi) signal, and the difference spectrum from which myocardial $\mathrm{pH}_{\mathrm{i}}$ was derived. Table 1 shows $\mathrm{P}_{\mathrm{a}} \mathrm{CO}_{2}$, myocardial $\mathrm{pH}_{\mathrm{i}}$ and arterial lactate and 3-hydroxybutyrate concentrations before and after treatment. The severity of the ketoacidosis is demonstrated by the pre-infusion arterial $\mathrm{pH}$ $\left(\mathrm{pH}_{\mathrm{a}}\right)$ and 3-hydroxybutyrate values which are similar for all groups. Arterial blood glucose was in the range of 15-22 mmol/l. The baseline levels of $\mathrm{P}_{\mathrm{a}} \mathrm{CO}_{2}$ were low in all groups, indicating that the artificial ventilation maintained a degree of respiratory compensation. Though no significant difference at baseline was seen between the groups in myocardial $\mathrm{pH}_{\mathrm{i}}$; there was a tendency for a lower mean value in the group that subsequently received saline.

The effect of treatment is also shown in Table 1. Marked and similar elevations of $\mathrm{pH}_{\mathrm{a}}$ were produced in the groups treated with sodium bicarbonate and 'Carbicarb', but there was no significant change in the saline group. In the sodium bicarbonate and 'Carbicarb' groups there were highly significant elevations in myocardial $\mathrm{pH}_{\mathrm{i}}$ (means 0.16 and $0.22 \mathrm{pH}$ units, respectively), and a slight but significant fall in the saline group. At the end of the infusion there was a significant elevation of $\mathrm{P}_{\mathrm{a}} \mathrm{CO}_{2}$ from baseline in the sodium bicarbonate and 'Carbicarb' groups, but not in the saline group. There were highly significant elevations of blood lactate in the alkali-treated groups, but that in the saline group was not significant. There was also significant elevation of blood 3- 

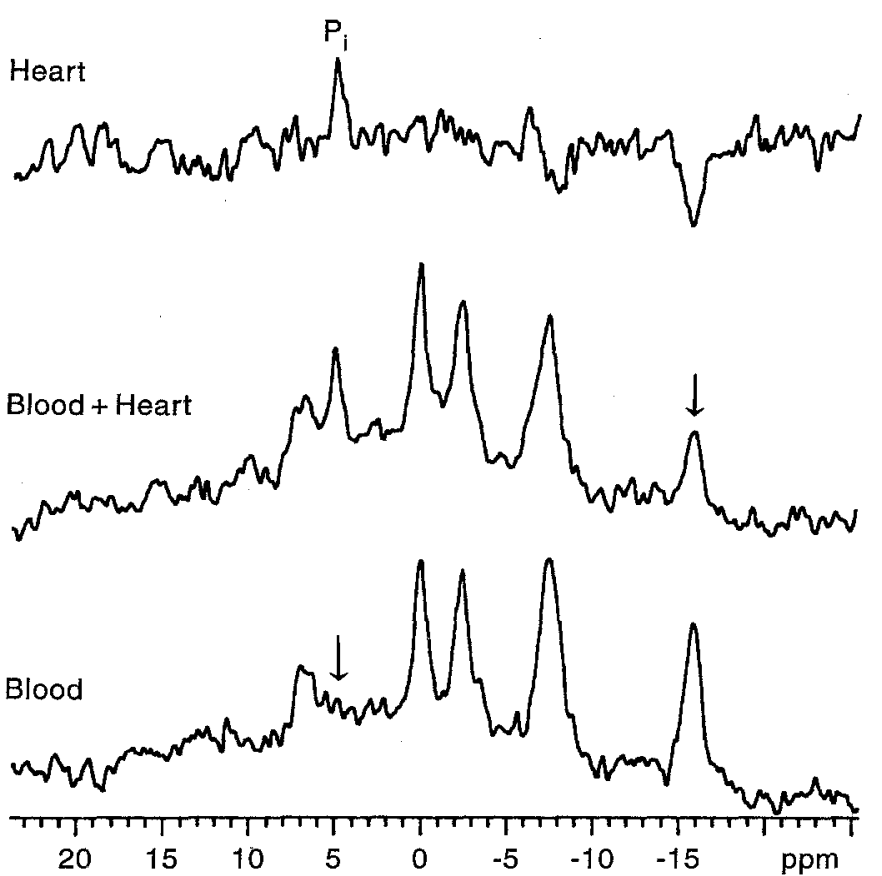

Fig. 1. ${ }^{31} \mathrm{P}-\mathrm{MRS}$ spectra of heart in vivo in animals with diabetic ketoacidosis. In the lowest spectrum the saturation pulse is at the position of the $\mathrm{Pi} / 2,3-\mathrm{BPG}$ signal; only myocardial $\mathrm{Pi}$ is saturated so the spectrum reflects that of the moving blood in the cardiac chambers. In the middle spectrum the frequency of the saturation pulse is at approximately the position of the $\beta$-ATP signal, which is partially suppressed, due to saturation of the myocardial component. The top spectrum is derived by subtraction of the lower from the middle spectrum, and shows the myocardial Pi peak, from the chemical shift of which $\mathrm{pH}_{\mathrm{i}}$ is derived. Because of the depletion of 2,3-BPG in the DKA animals, its resonance is virtually absent in these spectra

hydroxybutyrate in the sodium bicarbonate group. When treatment effects were compared between groups by analysis of variance, significances (Table 1) which were broadly similar to those found for comparisons of base-line adjusted post-treatment values were demonstrated for the different variables; however, elevation of lactate in the bicarbonate group compared with that in the saline group was of borderline significance $(p=0.038)$, and was highly significant for 'Carbicarb' $(p=0.008)$.

Table 2 provides data on several indices of myocardial energy status before and after saline or alkali therapy in the three groups. These data were obtained from the same experiments as in Table 1, but for each group the number of studies analysed was reduced by one because of unsatisfactory signal/noise ratio in the excluded studies. There was clearly no effect of saline on PCr/ATP, PCr/Pi and ATP/Pi. In the alkali-treated groups there was a trend to decreased $\mathrm{PCr} / \mathrm{Pi}$ and $\mathrm{ATP} / \mathrm{Pi}$ post-treatment, which almost reached conventional significance in the 'Carbicarb' group; if the data from both alkali-treated groups were pooled, the fall in both $\mathrm{PCr} / \mathrm{Pi}$ and ATP/Pi were significant at $p<0.05$; these statistics should,
Table 1. $\mathrm{pH}_{\mathrm{a}}, \mathrm{P}_{\mathrm{a}} \mathrm{CO}_{2}$, myocardial $\mathrm{pH}_{\mathrm{i}}$, blood lactate and 3-hydroxybutyrate in rats with diabetic ketoacidosis pre- and posttreatment with saline, sodium bicarbonate or 'Carbicarb'

\begin{tabular}{|c|c|c|c|}
\hline $\begin{array}{l}\text { Treatment } \\
\text { group }\end{array}$ & Saline & $\begin{array}{l}\text { Sodium } \\
\text { bicarbonate }\end{array}$ & 'Carbicarb' \\
\hline $\begin{array}{l}\text { Number in } \\
\text { group }\end{array}$ & 5 & 5 & 6 \\
\hline $\begin{array}{l}\text { Pre } \\
\text { Post }\end{array}$ & $\begin{array}{l}6.86 \pm 0.07 \\
6.77 \pm 0.03\end{array}$ & $\begin{array}{r}6.89 \pm 0.06 \\
\mathrm{~d} 7.17 \pm 0.03^{\mathrm{c}}\end{array}$ & $\begin{array}{r}6.91 \pm 0.05 \\
\mathrm{e} 7.21 \pm 0.03^{\mathrm{c}}\end{array}$ \\
\hline $\begin{array}{r}\text { Myocardial } \\
\text { Pre } \\
\text { Post }\end{array}$ & $\begin{array}{r}6.95 \pm 0.07 \\
\mathrm{~d} 6.89 \pm 0.08\end{array}$ & $\begin{array}{c}7.09 \pm 0.05 \\
\mathrm{e} 7.25 \pm 0.03^{\mathrm{c}}\end{array}$ & $\begin{array}{r}7.08 \pm 0.03 \\
\mathrm{e} 7.30 \pm 0.03^{\circ}\end{array}$ \\
\hline $\begin{array}{r}\mathrm{P}_{\mathrm{a}} \mathrm{CO}_{2}(\mathrm{kPa} \\
\text { Pre } \\
\text { Post }\end{array}$ & $\begin{array}{l}2.53 \pm 0.24 \\
2.89 \pm 0.15\end{array}$ & $\begin{array}{c}3.04 \pm 0.36 \\
d_{4.20 \pm 0.25^{a}}\end{array}$ & $\begin{array}{r}2.82 \pm 0.16 \\
\mathrm{e} 3.53 \pm 0.32\end{array}$ \\
\hline $\begin{array}{r}\text { Lactate }(\mathrm{mn} \\
\text { Pre } \\
\text { Post }\end{array}$ & $\begin{array}{l}\text { 1) } \\
1.50 \pm 0.22 \\
3.38 \pm 1.22\end{array}$ & $\begin{array}{c}0.98 \pm 0.13 \\
{ }^{\mathrm{e}} 6.81 \pm 1.06^{\mathrm{a}}\end{array}$ & $\begin{array}{c}1.16 \pm 0.12 \\
\mathrm{e} 8.21 \pm 1.30^{\mathrm{b}}\end{array}$ \\
\hline $\begin{array}{c}\text { 3-hydroxyb } \\
\text { Pre } \\
\text { Post }\end{array}$ & $\begin{array}{r}\text { ate }(\mathrm{mmol} / \mathrm{l}) \\
6.44 \pm 0.71 \\
6.69 \pm 0.91\end{array}$ & $\begin{array}{c}6.18 \pm 0.85 \\
\mathrm{~d} 9.56 \pm 1.27^{\mathrm{a}}\end{array}$ & $\begin{array}{l}7.93 \pm 0.47 \\
8.92 \pm 0.43\end{array}$ \\
\hline
\end{tabular}

Data are means \pm SEM. The significance of differences posttreatment from mean values in the saline group (having adjusted for baseline differences - see Methods) is given by: ${ }^{\mathrm{a}} p<0.05 ;{ }^{\mathrm{b}} p<0.01 ;{ }^{\mathrm{c}} p<0.001$. The significance of the mean difference within the same treatment group pre- and post-treatment is shown by: ${ }^{\mathrm{d}} p<0.05 ;{ }^{\mathrm{e}} p<0.01$

however, be treated with caution, since when the changes in these variables in the alkali-treated groups were compared with those in the saline group, they were not significantly different $(p=0.18$ and $p=0.19$, respectively).

Bench experiments. Table 3 shows the baseline values of $\mathrm{pH}_{\mathrm{a}}, \mathrm{P}_{\mathrm{a}} \mathrm{CO}_{2},\left[\mathrm{HCO}_{3}{ }_{\mathrm{a}}\right.$, blood lactate and 3-hydroxybutyrate. These were similar to those in the MRS studies (Table 1). The baseline mean arterial blood pressure (MABP) did not differ between the groups and the mean for each group was in the range 62-67 $\mathrm{mmHg}$. Comparison with our previous data and those of Zahler et al. [19] indicate that the present study animals were substantially hypotensive. Figure 2 shows the detailed time course of the changes in $\mathrm{pH}_{2}, \mathrm{P}_{\mathrm{a}} \mathrm{CO}_{2}$, blood lactate and MABP from the start of the 3-min infusion period until $20 \mathrm{~min}$ later. When all three treatment groups were compared in a single analysis of covariance, the means over time after commencement of treatment for arterial blood $\mathrm{pH},\left[\mathrm{HCO}_{3}^{-}\right]$and [lactate] were highly significantly different between the bicarbonate and saline groups and between the 'Carbicarb' and saline groups $(p=0.001)$. For $\mathrm{P}_{\mathrm{a}} \mathrm{CO}_{2}$, using analysis of covariance, the mean over time in the bicarbonate group was significantly greater than that in the saline group $(p=0.02)$; in contrast, the mean over time in the 'Carbicarb' group was not significantly different 

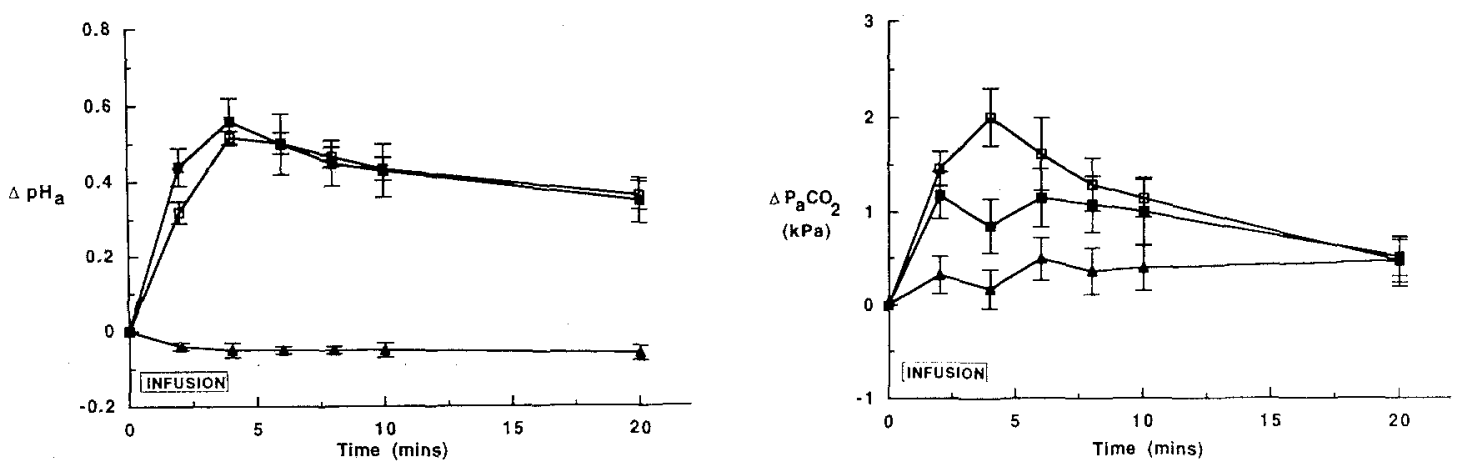

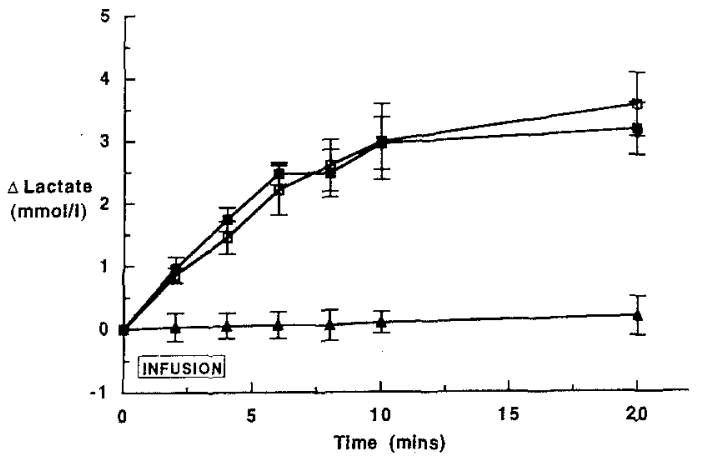

Fig. 2. Changes in arterial $\mathrm{pH}\left(\mathrm{pH}_{\mathrm{a}}\right), \mathrm{P}_{\mathrm{a}} \mathrm{CO}_{2}$, arterial blood lactate and mean arterial blood pressure in animals with DKA, during and after infusion of saline $(\boldsymbol{A})$, sodium bicarbonate ( $\square$ ) or 'Carbicarb' ( $\mathbf{a}$ ), as described in 'Methods'. The baseline data from these studies is given in Table 3. The error bars represent SEM; statistical analysis is given in the text

Table 2. Myocardial PCr/ATP, PCr/P and ATP/P $\mathrm{P}_{\mathrm{i}}$ before and after infusion into diabetic ketoacidotic rats of saline $(n=4)$, sodium bicarbonate $(n=4)$ or 'Carbicarb' $(n=5)$ in the ${ }^{31} \mathrm{P}$. magnetic resonance experiments

\begin{tabular}{|c|c|c|c|}
\hline Group & $\mathrm{PCr} / \mathrm{ATP}$ & $\mathrm{PCr} / \mathrm{P}_{\mathrm{i}}$ & $\mathrm{ATP} / \mathrm{P}_{\mathrm{i}}$ \\
\hline \multicolumn{4}{|l|}{ Saline } \\
\hline Pre & $1.32 \pm 0.17$ & $2.15 \pm 0.26$ & $1.65 \pm 0.14$ \\
\hline Post & $1.24 \pm 0.18$ & $2.14 \pm 0.54$ & $1.71 \pm 0.4$ \\
\hline \multicolumn{4}{|c|}{ Sodium bicarbonate } \\
\hline Pre & $1.41 \pm 0.31$ & $2.15 \pm 0.61$ & $1.50 \pm 0.36$ \\
\hline Post & $1.20 \pm 0.38$ & $1.51 \pm 0.89$ & $1.07 \pm 0.30$ \\
\hline \multicolumn{4}{|l|}{ 'Carbicarb' } \\
\hline Pre & $1.26 \pm 0.19$ & $2.00 \pm 0.53$ & $1.60 \pm 0.36$ \\
\hline Post & $1.15 \pm 0.10$ & $1.15 \pm 0.28$ & $0.99 \pm 0.18$ \\
\hline
\end{tabular}

Data are means \pm SEM. See text for statistical analysis

from that in the saline group $(p=0.09)$. The baseline value of $\mathrm{P}_{\mathrm{a}} \mathrm{CO}_{2}$ was not significantly associated with the post-treatment mean, so that analysis of variance gave $p=0.02$ and $p=0.03$ for the changes in the bicarbonate and 'Carbicarb' treated groups, respectively, compared with those in the saline group. For MABP (Fig. 2), the mean over time post-treatment was very significantly lower in the 'Carbicarb' group than in the saline group ( $p=0.01$ ); there was a similar trend in the comparison between the bicarbonate group and the saline group, but this difference just failed to reach conventional significance $(p=0.056)$. Comparing the bicarbonate and 'Carbicarb' groups alone, there were no significant differences over time for $\left[\mathrm{HCO}_{3}^{-}\right]$, [lactate], $\mathrm{P}_{\mathrm{a}} \mathrm{CO}_{2}, \mathrm{pH}_{\mathrm{a}}$ or MABP. However, with the numbers of animals used in each group in the present studies, only a difference as large as $12 \mathrm{~mm} \mathrm{Hg}$ in MABP could have been detected with $80 \%$ power (at $p=0.05$ ).

Erythrocyte 2,3-BPG was measured in arterial blood in a separate group of six control rats and six animals with DKA, at $48 \mathrm{~h}$ after injection of streptozotocin, i.e. at the point in the development of the condition when treatment was instituted in the MRS and bench studies. Figure 3 shows typical spectra in the $\mathrm{Pi} / 2,3-\mathrm{BPG}$ region. It is clear that 2,3-BPG is below the minimum detectable concentration $(0.3 \mathrm{mmol} / \mathrm{l}$ blood $)$ in blood from this DKA animal and this was also the case in the five other rats with DKA. In blood from normal rats the mean concentration of 2,3-BPG was $3.32 \pm 0.20 \mathrm{mmol} / 1$ blood, equivalent to $1.65 \mathrm{~mol}$ per mol haemoglobin.

\section{Hypovolaemic shock}

Table 4 shows baseline mean values of $\mathrm{pH}_{\mathrm{a}}, \mathrm{P}_{\mathrm{a}} \mathrm{CO}_{2}$ arterial blood [lactate] and MABP in the bench studies in the three treatments groups; these were similar, though small differences $(p<0.05)$ were seen in arterial lactate and MABP. It may be noted that the ani- 


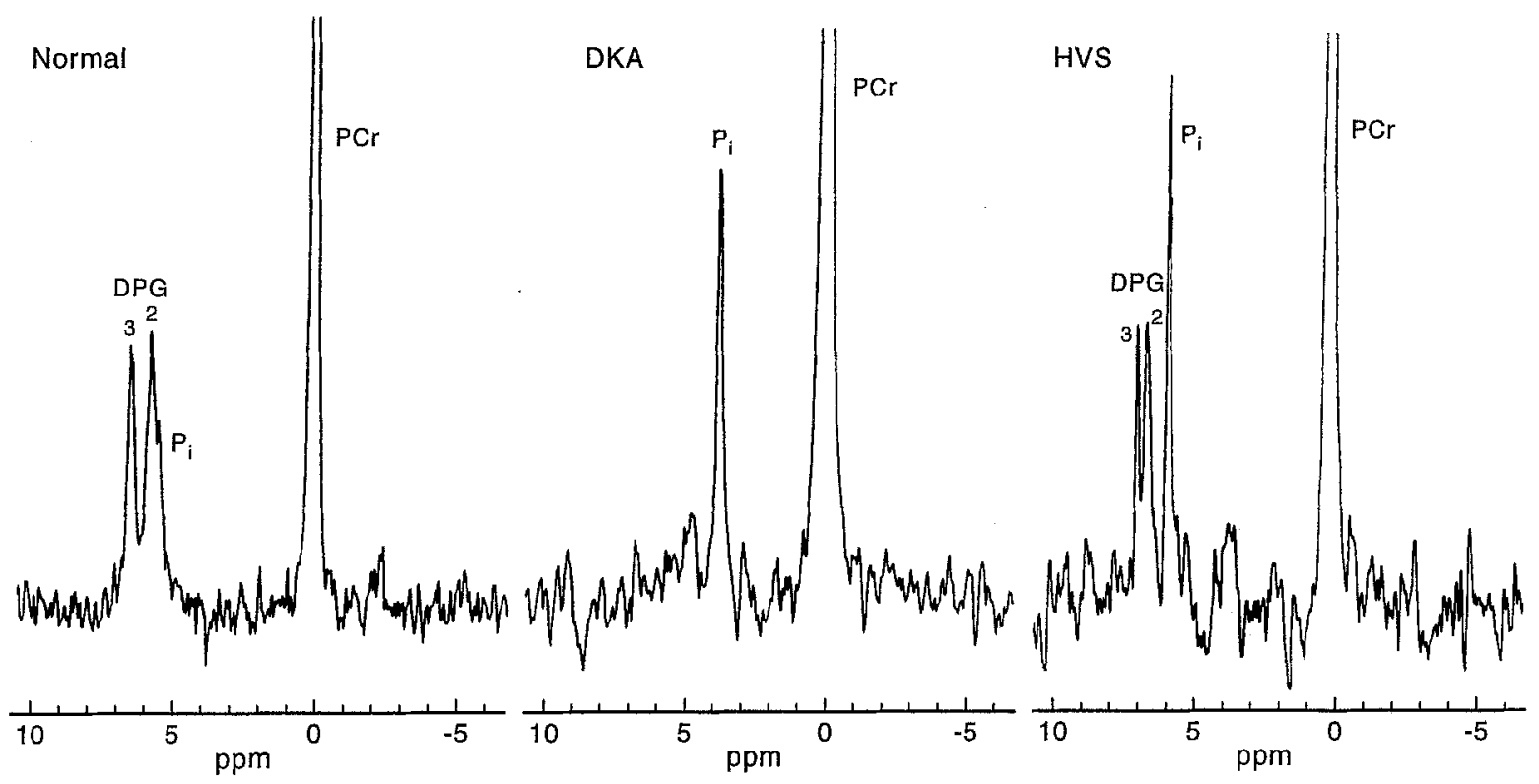

Fig. 3. ${ }^{31} \mathrm{P}-\mathrm{MRS}$ spectra of perchloric acid extracts of blood from normal (left), DKA (middle) and hypovolaemic shock (HVS) (right) rats. The largest resonance is that of phosphocreatine, added as a reference and quantification standard. Note the virtual absence of the 2,3-BPG signal in the extract from the DKA rat. The greater separation between the Pi and 2-P of DPG seen in the spectrum in the extract from the shocked animal compared with that from the normal animal is purely technical and is due to a minor difference in the neutralization of the perchloric extract

Table 3. Baseline $\mathrm{pH}_{\mathrm{a}}, \mathrm{P}_{\mathrm{a}} \mathrm{CO}_{2}$, blood lactate and hydroxybutyrate and mean arterial blood pressure (MABP) in groups of rats with diabetic ketoacidosis who were subsequently treated with saline, sodium bicarbonate or 'Carbicarb' in the 'bench' studies

\begin{tabular}{llll}
\hline Treatment group & Saline & $\begin{array}{l}\text { Sodium } \\
\text { bicarbonate }\end{array}$ & 'Carbicarb' \\
\hline Number of group & 5 & 5 & 6 \\
\hline $\mathrm{pH}_{\mathrm{a}}$ & $6.95 \pm 0.11$ & $6.84 \pm 0.04$ & $6.94 \pm 0.08$ \\
$\mathrm{P}_{\mathrm{a}} \mathrm{CO}_{2}(\mathrm{kPa})$ & $2.62 \pm 0.09$ & $2.67 \pm 0.15$ & $2.91 \pm 0.17$ \\
lactate $(\mathrm{mmol} / \mathrm{l})$ & $1.26 \pm 0.22$ & $1.10 \pm 0.25$ & $1.59 \pm 0.43$ \\
3-hydroxybu- & $5.19 \pm 0.91$ & $6.93 \pm 0.51$ & $6.86 \pm 0.41$ \\
tyrate $(\mathrm{mmol} / \mathrm{l})$ & & & $62.7 \pm 7.59$ \\
MABP $(\mathrm{mm} \mathrm{Hg})$ & $66.6 \pm 6.92$ & $63.8 \pm 6.52$ & 62.04 \\
\hline
\end{tabular}

Data are means \pm SEM. There were no statistically significant differences between the variables in any of the groups

mals were less acidotic, more hypotensive and had much higher blood lactate than in the DKA series. The time course of the changes in these variables on treatment is shown in Figure 4. There were, as expected, highly significant differences in the summary statistics analysis considering the three treatment groups together between the saline group on the one hand and the bicarbonate and 'Carbicarb' groups on the other for $\mathrm{pH}_{\mathrm{a}}(p<0.001)$; however, there were no significant differences in the mean post-treatment $\mathrm{P}_{\mathrm{a}} \mathrm{CO}_{2}$. For blood lactate, there was a trend towards a higher mean value in the 'Carbicarb' than in the saline group but this did not quite reach significance $(p=0.07)$. Though Figure 4 suggests that the mean post-treatment MABP was (in contrast to the findings in the DKA series) more favourable in the alkali-treated groups, neither in the bicarbonate group $(p=0.21)$ or in the 'Carbicarb' group $(p=0.84)$ was this significant. Comparing the two alkali groups alone, there were no significant differences in the summary statistics analysis for any variable.

Erythrocyte 2,3-BPG was measured (Fig. 3) in a separate series of five animals subjected to an identical protocol of blood withdrawal to induce hypovolaemic shock. Mean 2,3-BPG was $2.19 \pm 0.1 \mathrm{mmol} /$ 1 blood, which taking into account the haemodilution to a mean of $9.6 \pm 0.16 \mathrm{~g} / \mathrm{dl}$ seen in the hypovolaemic animals from the normal value of $13.1 \pm 0.47 \mathrm{~g} / \mathrm{dl}$ is equivalent to $1.46 \mathrm{~mol}$ per mol haemoglobin, similar to the value obtained in normal animals.

\section{Discussion}

These studies were designed to test the effects of different types of alkalinization on myocardial $\mathrm{pH}_{\mathrm{i}}$, MABP and blood lactate in an animal model of diabetic ketoacidosis, using acute hypovolaemia due to blood withdrawal as a model of a more acute metabolic acidosis for comparison. The studies were not intended to emulate therapeutic protocols for clinical diabetic ketoacidosis and hypovolaemic shock, but to examine some of the factors which determine the haemodynamic and metabolic response to bicarbonate and 'Carbicarb'. The results from the present studies cannot necessarily be 

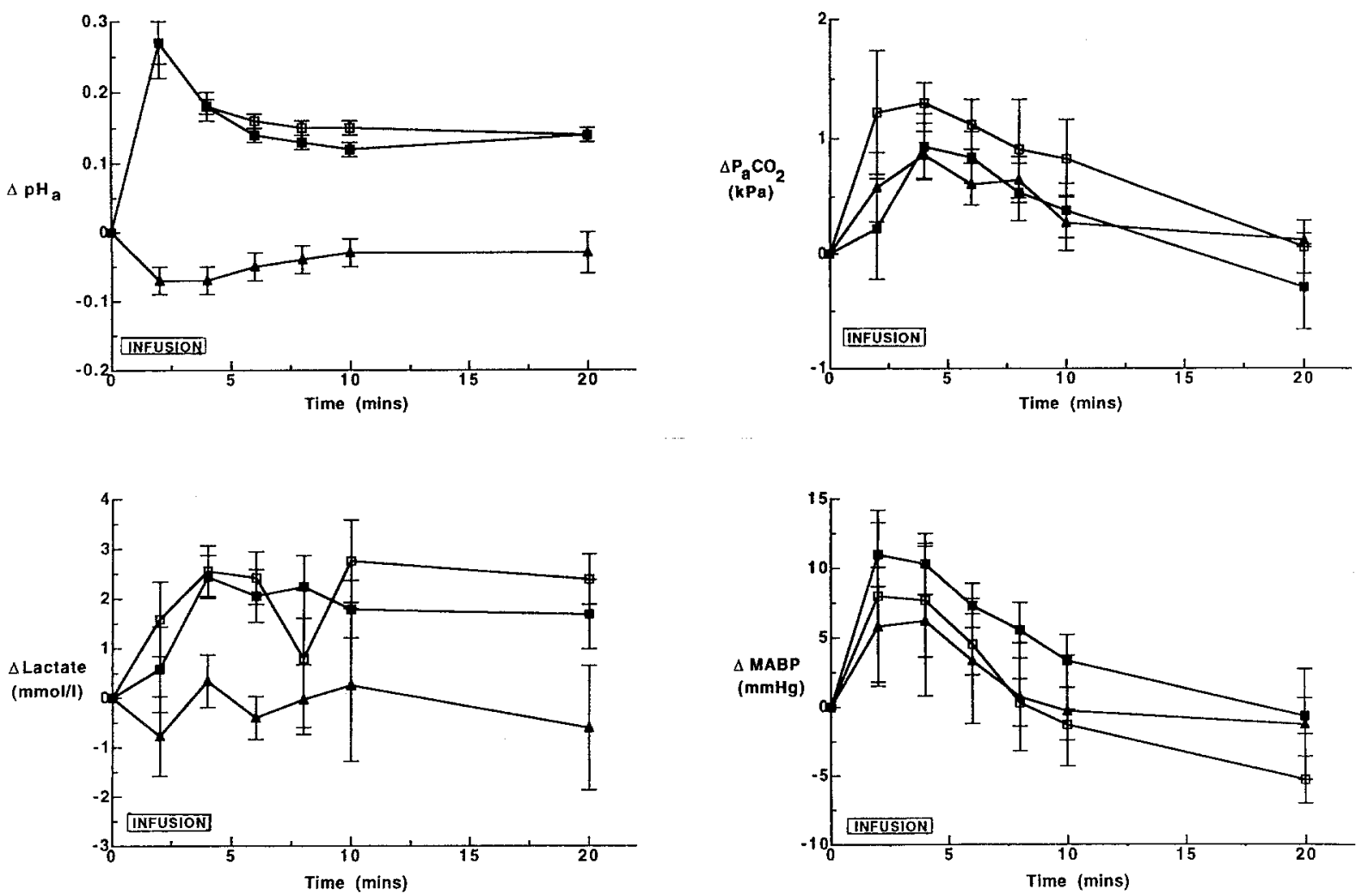

Fig. 4. Changes in arterial $\mathrm{pH}\left(\mathrm{pH}_{\mathrm{a}}\right), \mathrm{P}_{\mathrm{a}} \mathrm{CO}_{2}$, arterial blood lactate and mean arterial blood pressure in animals with hypovolaemic shock, during and after infusion of saline $(\boldsymbol{\Delta})$, sodium bicarbonate ( $\square$ ) or 'Carbicarb' $(\boldsymbol{\square})$, as described in 'Methods'. The baseline data from these studies is given in Table 4 . The error bars represent SEM; statistical analysis is given in the text

Table 4. Baseline $\mathrm{pH}_{\mathrm{a}}, \mathrm{P}_{\mathrm{a}} \mathrm{CO}_{2}$, arterial blood lactate and mean arterial blood pressure (MABP) in groups of rats with hypovolaemic shock who were subsequently treated with saline, sodium bicarbonate or 'Carbicarb'

\begin{tabular}{lccc}
\hline $\begin{array}{l}\text { Treatment } \\
\text { group }\end{array}$ & Saline & $\begin{array}{l}\text { Sodium } \\
\text { bicarbonate }\end{array}$ & 'Carbicarb' \\
\hline $\begin{array}{l}\text { Number in } \\
\text { group }\end{array}$ & 6 & 6 & 6 \\
\hline $\mathrm{pH}_{\mathrm{a}}$ & $7.26 \pm 0.013$ & $7.27 \pm 0.006$ & $7.28 \pm 0.007$ \\
$\mathrm{P}_{\mathrm{a}} \mathrm{CO}_{2}(\mathrm{kPa})$ & $3.84 \pm 0.17$ & $4.01 \pm 0.17$ & $4.08 \pm 0.18$ \\
$\begin{array}{l}\text { Lactate } \\
\text { (mmol/l) }\end{array}$ & $12.06 \pm 0.54$ & $9.21 \pm 0.51^{\mathrm{a}}$ & $10.59 \pm 0.41$ \\
$\begin{array}{l}\mathrm{MABP} \\
(\mathrm{mmHg})\end{array}$ & $40.7 \pm 0.88$ & $38.7 \pm 1.86$ & $36.0 \pm 1.44^{\mathrm{a}}$ \\
\hline
\end{tabular}

Data are means \pm SEM. ${ }^{\text {a Significantly different from the sa- }}$ line group $(0.05>p>0.01)$

extrapolated to other models differing in their pathophysiological status.

Because of the severity factor we found it more practical to perform a parallel series of bench experiments rather than sample from animals whilst in the

spectrometer; this allowed greater control over blood sampling and a detailed examination of the time course of the variables. Due to the acquisition time of the MRS procedure, it was not possible to obtain a detailed time course of myocardial $\mathrm{pH}_{\mathrm{i}}$, the single post-treatment value obtained being regarded as a time-averaged mean of the post-infusion values. The baseline data in the bench studies in DKA animals closely resemble those in the MRS studies. We therefore assume that the detailed subsequent time courses of the variables studied were similar in the MRS and bench studies. It should be noted that because of the decrease of erythrocyte 2,3-BPG to unrecordable levels in the animals with DKA, the MRS subtraction technique was only concerned with removal of the error from blood $\mathrm{Pi}$ in the ventricular cavity.

The most striking findings in the DKA model are the substantial rise in myocardial $\mathrm{pH}_{i}$ that occurred on infusion of sodium bicarbonate or 'Carbicarb', the deleterious effects on MABP and the marked rise in blood lactate that were seen in the alkali-treated groups but not in the saline group. The rise in myocardial $\mathrm{pH}_{\mathrm{i}}$ during bicarbonate infusion contrasts with the findings of Zahler et al. [19] in rats receiving acute lactic acid infusions; they observed no significant change in either myocardial $\mathrm{pH}_{\mathrm{i}}$ or systolic blood pressure. In the study of Rhee et al. [25] in dogs with acute hypoxic lactic acidosis, myocardial $\mathrm{pH}_{\mathrm{i}}$ was stated to have improved more with 'Carbicarb' than with sodium bicarbonate or chloride. There was a positive relationship between $\mathrm{pH}_{\mathrm{a}}$ and 
$\mathrm{pH}_{\mathrm{i}}$ which was similar in all treatment groups in that study, but subtraction techniques were not used to eliminate contributions to the signals from intracavitary Pi and 2,3-BPG; cardiac index was more favourably affected with 'Carbicarb' than with saline, and MABP was better sustained in both alkali-treated groups than with saline. In a similar study in acute hypoxic lactic acidosis in rats, Sun et al. [26] found that 'Carbicarb' had advantages over bicarbonate in respect of $\mathrm{pH}_{\mathrm{a}}, \mathrm{MABP}$ and blood lactate, but did not measure myocardial $\mathrm{pH}_{\mathrm{i}}$.

Since myocardial $\mathrm{pH}_{\mathrm{i}}$ rose in the alkali-treated rats with DKA, the relative post-treatment hypotension in those groups cannot be attributed to the negative inotropic effect of myocardial acidification, which has been proposed as a reason for the adverse haemodynamic effect of sodium bicarbonate in metabolic acidosis due to ventilation with hypoxic gas mixtures [9]. Indeed, the data of Steenbergen et al. [13] suggests that the rise in $\mathrm{pH}_{\mathrm{i}}$ seen in the present studies would, if taking place in the absence of other factors, have produced a significant positive inotropic effect. The cause of the relative hypotension in the alkalitreated groups remains to be conclusively demonstrated. However, the present observations are consistent with the suggestion that it was due to the effect on cardiac function of alkali-induced acute left shift of the haemoglobin-oxygen dissociation curve on a background of the marked depletion observed of erythrocyte 2,3-BPG. Data in human erythrocytes [27] suggest a decrease in $\mathrm{P}_{50}\left(\mathrm{PO}_{2}\right.$ at half saturation of haemoglobin) of approximately $0.13 \mathrm{kPa}$ (1 $\mathrm{mm} \mathrm{Hg}$ ) for each decrement of $0.1 \mathrm{~mol} \mathrm{2,3-BPG/}$ mol haemoglobin. The tendency to lowering of myocardial energy status ( $\mathrm{PCr} / \mathrm{Pi}$ and $\mathrm{ATP} / \mathrm{Pi})$ and the substantial elevation of blood lactate in both alkalitreated groups are consistent with induced myocardial and general tissue hypoxia. Other explanations for the hypotension in the alkali-treated groups are possible; for example, if the infusion of alkali produced peripheral vasodilatation, but that of saline did not. We believe this to be less likely, since no such differential effect of alkalinization occurred in the animals with hypotension due to blood withdrawal.

The time course of $\mathrm{P}_{\mathrm{a}} \mathrm{CO}_{2}$ was significantly elevated in the bicarbonate group over that in the saline group. Yet, in both alkali-treated groups there was an elevation of the time-averaged myocardial $\mathrm{pH}_{\mathrm{i}}$. However, in our studies [20] of skeletal muscle $\mathrm{pH}_{\mathrm{i}}$ response to sodium bicarbonate and 'Carbicarb' in haemorrhagic shock, a similar differential in the course of $\mathrm{P}_{\mathrm{a}} \mathrm{CO}_{2}$ was also not reflected in $\mathrm{pH}_{\mathrm{i}}$, which in that study could be measured at 60 -s intervals, because of the availability of the carbon- 2 proton resonance of anserine for $\mathrm{pH}_{\mathrm{i}}$ determination by the more sensitive proton MRS. Furthermore, in the isolated rat liver perfused at acidotic $\mathrm{pH}$, hepatic $\mathrm{pH}_{\mathrm{i}}$ rises on infusion of bicarbonate, despite a substantial elevation of portal vein $\mathrm{PCO}_{2}$ [28]. There are clearly determinants of $\mathrm{pH}_{\mathrm{i}}$ other than $\mathrm{P}_{\mathrm{a}} \mathrm{CO}_{2}[20]$ and we regard the argument concerning paradoxical intracellular acidification during bicarbonate therapy as of doubtful importance [29]. The risk of such acidification could in any case be eliminated in most clinical situations by slower infusion of bicarbonate than is often customary, thereby allowing respiratory elimination of $\mathrm{CO}_{2}$ released by titration of bicarbonate [30].

There was a marked effect of both alkalinizing agents in elevating blood lactate in rats with DKA. However, in a model of severe diabetic ketoacidosis identical to the present one except that it was not necessary to use artificial ventilation, we found no rise in lactate on bicarbonate infusion [28]. Nor in the study of skeletal muscle $\mathrm{pH}_{\mathrm{i}}$ in hypovolaemic shock referred to above [20], in which the protocol was similar to that in the present studies, except that thoracotomy and artificial ventilation were not employed, was any elevation of blood lactate observed on infusion of either bicarbonate or 'Carbicarb'. It therefore appears likely that the effect on blood lactate in the present study requires a background of artificial ventilation. Since we have demonstrated that bicarbonate markedly improves disposal of lactate in livers from acidotic and normal rats perfused at $\mathrm{pH} 6.8$, we suggest that in the absence of artificial ventilation increased hepatic uptake of lactate during bicarbonate infusion compensates for increased peripheral production of lactate. However, during positive pressure ventilation the haemodynamic effects of the procedure could decrease hepatic blood flow and thereby impair lactate disposal [31]. Under these circumstances, increased peripheral lactate production would result in hyperlactataemia. Factors leading to elevated lactate production include left shift of the oxygen dissociation curve, the relative hypotension itself and intracellular alkalinization, which counteracts acidotic inhibition of glycolysis at the 6-phosphofructose 1-kinase step [32,3]. The elevation of blood 3-hydroxybutyrate seen after bicarbonate (Table 1) is presumably due to release of acidotic inhibition of ketogenesis [34], though the change after 'Carbicarb' is not significant.

The results of alkali treatment in the hypovolaemic shock series differed from those in the DKA animals. Instead of the deterioration in MABP seen in the latter series, there was a transient elevation in all treatment groups, with no significant difference between them. A similar pattern of response was observed in our previous study of skeletal muscle $\mathrm{pH}_{\mathrm{i}}$ in hypovolaemic shock [20]. Nor was significant elevation of blood lactate observed over the initial high values. Both DKA and hypovolaemic shock animals had been subjected to thoracotomy and similar artificial ventilation, to eliminate these factors as contributing to the different responses to alkali. No- 
tably, erythrocyte $2,3-\mathrm{BPG}$ was unchanged from nor$\mathrm{mal}$ in the hypovolaemic animals, when expressed in functional terms (mol per mol haemoglobin). We attribute this maintenance of 2,3-BPG to the short duration of the acidosis compared with that in the DKA animals, who had been developing the condition over $48 \mathrm{~h}$. Mild acidosis induced by ingestion of ammonium chloride has been shown over several days to lower 2,3-BPG in man [27], and there is marked depletion in patients with DKA [35].

It thus appears likely that both acidosis of many hours duration, leading to 2,3-BPG depletion, and artificial ventilation were required to produce the deleterious response to alkali in the DKA animals. However, it is possible that the lesser degree of acidosis and the more marked hypotension in the hypovolaemic shock series could be additional factors in the differing responses. These studies indicate the substantial range of factors which might determine the response to alkali in clinical metabolic acidosis and suggest that the problem in establishing whether alkali therapy is of clinical benefit [36] may be due to the difficulty in controlling for these factors in the clinical studies that have been attempted. Finally, the results of the present studies give no support to the idea that 'Carbicarb' may be a useful addition to clinical therapeutic options for DKA and hypovolaemic lactic acidosis. No evidence of its haemodynamic or metabolic advantage was seen; particularly in acidoses of substantial duration such as DKA it might be expected to be less satisfactory than bicarbonate, since the effect of the latter in raising $\mathrm{P}_{\mathrm{a}} \mathrm{CO}_{2}$ might be expected partially to counter the left shift of the oxygen dissociation curve, an effect which would be absent with 'Carbicarb'.

Acknowledgements. This work was supported by Grant No. G8902537SB awarded by the UK Medical Research Council. Magnetic resonance spectroscopy data was acquired at the University of London Intercollegiate Research Service (ULIRS) facility at Queen Mary and Westfield College, London.

\section{References}

1. Lever E, Jaspan JB (1983) Sodium bicarbonate therapy in severe diabetic ketoacidosis. Am J Med 75: 263-268

2. De Fronzo RA, Matsuda M, Barrett EJ (1994) Diabetic ketoacidosis: a combined metabolic-nephrologic approach to therapy. Diabetes Reviews 2: 209-238

3. Graf H, Leach W, Arieff AI (1985) Metabolic effects of sodium bicarbonate in hypoxic dogs. Am J Physiol 249: F630F635

4. Arieff AI, Leach W, Park R, Lazarowitz VC (1982) Systemic effects of $\mathrm{NaHCO}_{3}$ in experimental lactic acidosis in dogs. Am J Physiol 242: F586-F591

5. Stacpoole PW (1986) Lactic acidosis: the case against bicarbonate therapy. Ann Intern Med 105: 276-279

6. Filley GF, Kindig N (1984) 'Carbicarb', an alkalinizing iongenerating agent of possible clinical usefulness. Trans Am Clin Climatol Assoc 96: 141-153
7. Ritter JM, Doktor HS, Benjamin N (1990) Paradoxical effect of bicarbonate on cytoplasmic pH. Lancet 335: 12431246

8. Weil MH, Rackow EC, Trevino R et al. (1986) Difference in acid-base state between venous and arterial blood during cardiopulmonary resuscitation. New Eng J Med 315: $153-156$

9. Bersin RM, Arieff AI (1988) Improved hemodynamic function during hypoxia with 'Carbicarb', a new agent for the management of acidosis. Circulation 77: 227-233

10. Iberti TJ, Kelly KM, Gentili DR et al. (1988) Effects of sodium bicarbonate in canine hemorrhagic shock. Crit Care Med 16: 779-782

11. Shapiro II (1990) Functional and metabolic responses of isolated hearts to acidosis: effects of sodium bicarbonate and 'Carbicarb'. Am J Physiol 258: H1835-H1839

12. Shapiro JI, Whalen M, Kucera R et al. (1989) Brain responses to sodium bicarbonate and 'Carbicarb' during systemic acidosis. Am J Physiol 256: H1316-H1321

13. Steenbergen C, Deleeuw G, Rich T, Williamson JR (1977) Effects of acidosis and ischemia on contractility and intracellular pH of rat heart. Circ Res 41: 849-858

14. Vogel S, Sperelakis N (1977) Blockade of myocardial slow calcium channels at low pH. Am J Physiol 233: C99-C103

15. Iles RA, Cohen RD, Rist AH, Baron PG (1977) The mechanism of inhibition by acidosis of gluconeogenesis from lactate in rat liver. Biochem J 164: 185-191

16. Iles RA, Cohen RD, Baron PG (1978) Effect of varying $\mathrm{PCO}_{2}$ on intracellular $\mathrm{pH}$ and lactate consumption in the isolated perfused rat liver. Clin Sci Mol Med 55: 175-181

17. Beech JS, Williams SR, Cohen RD, Iles RA (1989) Gluconeogenesis and the protection of hepatic intracellular $\mathrm{pH}$ during diabetic ketoacidosis in rats. Biochem J 263: 737-744

18. Zahler R, Majumdar S, Frederick B et al. (1991) NMR determination of myocardial $\mathrm{pH}$ in vivo: separation of tissue inorganic phosphate from blood 2,3-DPG. Magn Res Med 17: 368-378

19. Zahler R, Barrett E, Majumdar A et al. (1992) Lactic acidosis: effect of treatment on intracellular $\mathrm{pH}$ and energetics in living rat heart. Am J Physiol 262: H1572-H1578

20. Beech JS, Nolan KM, Iles RA et al. (1994) The effects of sodium bicarbonate and a mixture of sodium bicarbonate and carbonate ('Carbicarb') on skeletal muscle $\mathrm{pH}$ and haemodynamic status in rats with hypovolemic shock. Metabolism 43: 1-7

21. Hohorst HJ (1962) L(+)lactate determination with lactate dehydrogenase and NAD. In: Bergmeyer HU (ed) Methods of enzymatic analysis. Academic Press, New York NY. pp 266-270

22. Williamson DH, Mellanby J, Krebs HA (1962) Enzymatic determination of $\mathbf{D}(-)-\beta$-hydroxybutyric and acetoacetic acid in blood. Biochem $\mathrm{J}$ 82:90 98

23. Matthews JNS, Altman DG, Campbell MJ, Royston JP (1989) Analysis of serial measurements in medical research. BMJ 300: 230-235

24. Frison L, Pocock SJ (1992) Repeated measures in clinical trials: analysis using mean summary statistics and its implications for design. Statistics Medicine 11: 1685-1704

25. Rhee KH, Toro LO, McDonald GG et al. (1993) Carbicarb, sodium bicarbonate and sodium chloride in hypoxic lactic acidosis. Chest 104: 913-918

26. Sun JH, Filley GF, Hord K et al. (1987) Carbicarb: an effective substitute for $\mathrm{NaHCO}_{3}$ for the treatment of acidosis. Surgery 102: 835-839

27. Bellingham A, Detter JC, Lenfant C (1971) Regulatory mechanisms of hemoglobin-oxygen affinity in acidosis and alkalosis. J Clin Invest 50: 700-706 
28. Beech JS, Iles RA, Cohen RD (1993) Bicarbonate in the treatment of metabolic acidosis: effects on hepatic intracellular $\mathrm{pH}$ and lactate disposal in rats. Metabolism 42: 341346

29. Cohen RD (1990) When is bicarbonate appropriate in treating metabolic acidosis, including diabetic ketoacidosis? In: Gitnick G (ed) Debates in medicine. ( $3^{\text {rd }}$ edn) Year Book Medical Publishers, Inc., Chicago pp 202-210

30. Hindman BJ (1990) Sodium bicarbonate in the treatment of subtypes of acute lactic acidosis: physiologic considerations. Anesthesiol 72: 1064-1076

31. Iles RA, Baron PG, Cohen RD (1979) The effect of reduction of perfusion rate on lactate and oxygen uptake, glucose output and energy supply in the isolated perfused liver of starved rats. Biochem J 184: 635-642
32. Ui M (1966) A role of phosphofructokinase in $\mathrm{pH}$-dependant regulation of glycolysis. Biochim Biophys Acta 124: $310-322$

33. Trivedi B, Danforth WH (1966) Effect of pH on the kinetics of frog muscle phosphofructokinase. J Biol Chem 241: $4110-4112$

34. Hood VL, Tannen RL (1994) Maintenance of acid-base homeostasis during ketoacidosis and lactic acidosis. Diabetes Reviews 2: 177-194

35. Alberti KGMM, Darley JH, Emerson PM, Hockaday TDR (1972) 2,3-bisphosphoglycerate and tissue oxygenation in uncontrolled diabetes mellitus. Lancet 3: 391-395

36. Cooper DJ, Walley KR, Wiggs BR, Russell JA (1990) Bicarbonate does not improve hemodynamics in critically ill patients who have lactic acidosis. Ann Intern Med 112: 492-498 